\title{
Facility Location for Solid Waste Management through Compilation and Multicriterial Ranking of Optimal Decentralised Scenarios: A Case Study for the Region of Peloponesse in Southern Greece
}

\author{
A. Karagiannidis*, G. Perkoulidis, N. Moussiopoulos and M. Chrysochoou \\ Laboratory of Heat Transfer and Environmental Engineering, Department of Mechanical Engineering, Box 483, Aristotle \\ University, GR 54124 Thessaloniki

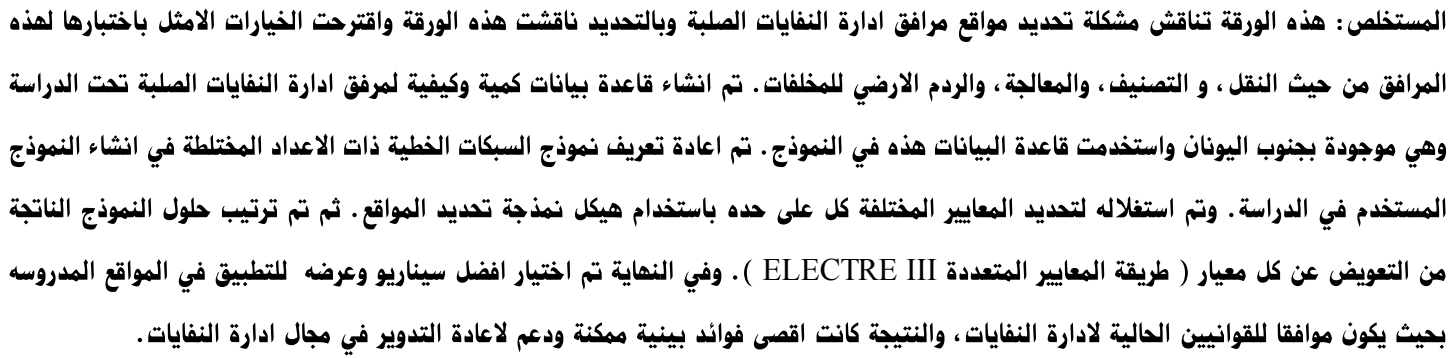 \\ الهفردات الهفتاحية: إدارة النفايات الصلبة، مواقع ، مرافق. النهوذج الذطي ذو الأعداد الهختطة، طريقة الهعايير البتعددة
}

\begin{abstract}
The present paper addresses the problem of locating solid waste management facilities. Specifically, it studies and proposes optimal alternative solutions for the Greek Region of Peloponnese, by examining facilities for transferring, sorting, treating and landfilling of wastes. Quantitative and qualitative databases concerning the current solid waste management at the Region have been created and used by the model. A customized mixed-integer linear network model has been developed and solved for various evaluation criteria on a single-criterion basis by the use of a location-allocation modeling framework. The solutions resulting from the parametrical application of the multicriterial method ELECTRE III are then ranked for the entire criteria-spectrum. The best alternative scenario is presented for the Region in accordance with current legislation on waste management, which maximizes environmental benefits and promotes recycling, in the frame of sustainable waste management.
\end{abstract}

Keywords: Solid waste management, location, facilities, mixed integer linear model, multicriterial method, ELECTRE III

\section{Notation}
$\mathrm{A}^{\mathrm{M}} \quad$ Coefficient for calculating the material recovery from waste
$\mathrm{t} \cdot$ day $/ \mathrm{t}_{\text {waste }} \cdot$ year
$\tilde{A}^{\mathrm{E}} \quad$ Energy recovery coefficients concerning corresponding waste
$\mathrm{MWh} \cdot \mathrm{day} / \mathrm{t}_{\text {waste }} \cdot$ year
$\AA_{\hat{1}}^{\AA} \quad$ Energy recovery coefficients concerning corresponding waste management facilities (rotary kiln and RDF facilities) management facilities (landfills)
$\tilde{A}_{i}^{\mathrm{GHE}} \quad$ Emission coefficients for greenhouse effect concerning rotary kiln and RDF facilities
$\AA_{i}^{\text {GHE }} \quad$ Emission coefficients for greenhouse effect concerning landfills
$\ddot{a}$
Landfill capacity
$\mathrm{MWh} \cdot \mathrm{day} / \mathrm{t}_{\text {waste }} \cdot$ year
eq. tco $_{2} \cdot$ day $/ t_{\text {waste }} \cdot$ year
eq. tco $_{2} \cdot$ day $/ t_{\text {waste }} \cdot$ year $\mathrm{t}_{\text {waste }} /$ day

*Corresponding author E-mail:makis@mix.meng.auth.gr 


\begin{tabular}{|c|c|c|}
\hline ì & Local transfer stations typologies & - \\
\hline í & Material recovery facilities typologies & - \\
\hline$\hat{\imath}$ & Incineration facilities typologies & - \\
\hline $\mathrm{o}$ & Typologies of landfills & - \\
\hline ð & Local transfer station system & - \\
\hline$\tilde{\mathrm{n}}$ & Material recovery facility & - \\
\hline ó & Waste-to-energy facility & - \\
\hline ò & $\begin{array}{l}\text { Uncompressed waste flow from local transfer station to the material } \\
\text { recovery facility }\end{array}$ & $\mathrm{t}_{\text {waste }} /$ day \\
\hline ô & Landfill & - \\
\hline$\ddot{O}^{i ̀}$ & Binary variable for locating local transfer stations & 0 or 1 \\
\hline$\stackrel{\dot{1}}{\circ} \tilde{\mathrm{n}}$ & Binary variable for locating material recovery facilities & 0 or 1 \\
\hline$\varnothing^{\hat{1}}{ }_{0}$ & Binary variable for locating waste -to-energy facilities & 0 or 1 \\
\hline$\grave{u}^{\ddot{i}}{ }_{0}$ & Binary variable for locating landfills & 0 or 1 \\
\hline$b^{\delta}$ & Flow of waste from producer to transfer station $ð$ & $\mathrm{t}_{\mathrm{waste}} /$ day \\
\hline c & Flow of waste to material recovery facility & $\mathrm{t}_{\mathrm{waste}} /$ day \\
\hline $\mathrm{d}$ & Flow of waste to waste -to-energy facility & $\mathrm{t}_{\mathrm{waste}} /$ day \\
\hline e & Flow of waste to landfill & $\mathrm{t}_{\text {waste }} /$ day \\
\hline $\mathrm{f}^{v}$ & Efficiency degree of material recovery facilities & $\%$ \\
\hline$f^{\hat{\imath}}$ & Efficiency degree of energy recovery facilities & $\%$ \\
\hline g & Upper limit to the capacity of material recovery facilities & t/day \\
\hline $\mathrm{h}$ & Upper limit to the capacity of waste -to-energy facilities & t/day \\
\hline $\mathrm{k}$ & Upper limit to the capacity of local transfer station & t/day \\
\hline $\mathrm{MR}_{\mathrm{j}}$ & Objective function concerning the material recovery from wastes & t/year \\
\hline$q^{\hat{1}}$ & Residues from waste -to-energy facility & t/day \\
\hline$s^{1}$ & Wastes and residues from material recovery facility & t/day \\
\hline $\mathrm{u}$ & Upper limit to the landfill capacity & t/day \\
\hline
\end{tabular}

\section{Introduction}

Environmental protection gained importance in legal, economical and technical terms in Greece (European Parliament and Council, 1994, Joined Ministerial Decision 114218, 1997; Joined Ministerial Decision 69728/824, 1996; Joined Ministerial Decision 113944, 1997). The location of facilities for integrated solid waste treatment and disposal has evolved into a complex issue during the recent years. Furthermore, public acceptance and social opposition are exercising pressure that brings such issues at the top of the political agenda. This trend (in Greece) gradually leads into interesting developments in the field of municipal waste management.

In the late nineties, research focused on implementing the integrated management of municipal waste in various areas in Greece (Karagiannidis and Moussiopoulos, 1997; Karagiannidis, 1998; Perkoulidis et al., 1998). Furthermore, according to the new European legislation (European Parliament and Council, 1994a), several studies were conducted with regard to integrated solid waste management at prefectural level (Karagiannidis et al., 1998; Moussiopoulos et al., 1998; Anatoliki, 1999, Association of Thessaloniki Municipalities, 1999, Perkoulidis et al., 1999; Kouras et al., 2001, Moussiopoulos, 2000; Moussiopoulos et al., 2002).

In order to reduce costs resulting from waste collection and material recovery, fixed and mobile transfer stations are proposed at the Region of Peloponnese, thus discour- aging illegal dumping to the over 1,000 existing uncontrolled landfills at this Region (Drossos and Terzopoulos, 1999). It must be pointed out that some material recovery facilities and sanitary landfills are currently in operation at this Region. These facilities should be taken into account during the regional planning for solid waste management, as this is outlined by Greek legislation (Official Journal of the Greek Government, 1999).

\section{Background of Modelling Techniques}

Various deterministic mathematical programming models have been used for planning solid waste management systems. Linear programming (Hsieh and Ho, 1993; Lund and Tchobanoglous, 1994), mixed integer programming (Anderson, 1968; Fuertes at al., 1974; Gottinger, 1986; Zhu and ReVelle, 1990), dynamic programming (Huang et al., 1992) and multiobjective programming (Perlack and Willis, 1985) are included in these deterministic modelling techniques.

A review of the various methods regarding sitting of facilities related with municipal solid waste management, was presented by Karagiannidis et al., 2002. Anderson and Nigam (1967) examined closely the cost minimisation of waste flows from transfer stations to landfills through the implementation of a branch and bound system. Furthermore, they developed an in-kilter algorithm, which disregarded, however, the existence of mass holes (Gottinger, 1988). A mathematical model for selection 
between alternative solid waste management systems with linear constraints and a non-linear objective function was presented by Helms and Clark (1971). Waste-to-energy facilities and sanitary landfills were considered as candidate facilities by the system. Fixed costs were related to binary variables (0-1), while linear transportation and treatment costs to continuous variables. Helms and Clark considered that residues from waste-to-energy facilities were driven to existing landfill sites.

Marks and Liebman (1970) dealt with the problem of transfer stations location by minimization of the total cost. A brunch and bound system was adopted using the Fulkerson algorithm (1961). Rossman (1971) extended the aforementioned study by adding waste-to-energy facilities in the set of candidate facilities. Esmaili (1972) proposed an optimisation model for minimizing total waste management costs. Gottinger (1998) and Kirca and Erkip (1988) consider the objective function of transportation costs as linear. Erkut and Neuman (1992) created a multi-objective model for locating undesirable facilities through minimization of the total cost. Finally, Caruso et al. (1993) studied the entire range of components that make up the integrated solid waste management system.

The selection of the multicriterial method for the evaluation of solid waste management systems could be characterized as a post-multicriterial problem. Saaty and Alexander (1981) compared candidate areas for locating an undesirable facility through implementation of the Analytic Hierarchy Process (AHP). Vuk and Ko $\square$ elj (1991) presented Promethee and Gaia for the selection of a landfill in Slovenia, while Hokkanen and Salminen (1994) implemented ELECTRE III for the selection of a solid waste management system in Finland. Karagiannidis and Moussiopoulos (1997) compared integrated solid waste management systems for the Greater Athens Area, Greece, taking into account 25 criteria with ELECTRE III, which was also used for the same purpose in other Regions in Greece (Perkoulidis, 2001).

\section{Objectives}

The main objective of the work presented in this paper is the determination of the best location for solid waste management facilities (transfer stations, material recovery facilities, waste-to-energy facilities, landfills), as well as the allocation of wastes (from municipal waste producers and transfer stations) and residues (from treatment facilities). The following steps were followed for the selection of the best alternative solid waste management scenario in the Region of Peloponnese:

- Creation of quantitative and qualitative databases on produced amount of wastes as well as on residues and quantitative analysis respectively per waste producer (municipality). This data was obtained by recording the current status of solid waste management in the Region of Peloponnese.
- Elaboration of the databases with the main characteristics of the existing and candidate solid waste management facilities. These concern mainly the capacity, the investment and operation cost, the amount of recovered energy and the emissions of each facility.

- Definition of linear objective functions through regression analysis. For the determination of these functions, the aforementioned databases (main characteristics of facilities) were used. Each objective function was sequentially adapted to each from a set of criteria; its value was determined as performance.

- Calculation of performances of each criterion. These resulted from the optimisation of the aforementioned objective functions.

- Application of a multicriterial method, in order to evaluate the aforementioned performances.

- Sensitivity analysis in order to derive the frequency distribution of each scenario's ranking from best to worst and lead to the proposal of the best alternative solid waste management scenario.

\section{Methodology}

The hierarchical facility location system comprises the following four primary levels (European Parliament and Council, 1994; Fishbein and Gelb, 1992 - Figure 1): (Level-a) transfer stations, (Level-b) material recovery facilities, (Level-c) waste-to-energy facilities, and (Leveld) sanitary landfills. A customized mixed-integer linear model is derived in a spreadsheet environment for the studied area by the use of a recent location-allocation, modelling framework (Karagiannidis and Moussiopoulos, 1998; Perkoulidis et al., 1998).

Binary variables set equal to 1 (treated as constants) are the two existing facilities (one landfill in Patra and one material recovery facility in Kalamata), as well as the thirty-six considered transfer stations. The latter is assumed due to the relatively bad rural road network, which makes the use of transfer stations necessary. As waste producers the municipalities at the Region of Peloponnese were considered.

An objective function is sequentially adapted to each criterion from a set of five evaluation criteria used in the present study:

Criterion-1 Greenhouse Effect (GHRE): $\mathrm{CO}_{2}$ equivalent of $\mathrm{CO}_{2}$ and $\mathrm{CH}_{4}$ emitted from facilities operation and residue transportation (kt/year to be minimized Equation 1, c.f, Figure 1). The values of $\Gamma_{\xi^{\mathrm{GHE}}}$ and $E_{o} G H E$ are given in Table 1.

$$
\begin{aligned}
\min G H E & =\sum_{\xi} \sum_{\sigma}\left(\Gamma_{\xi}^{G H E} \cdot d_{\sigma}^{\xi}\right) \\
& +\sum \sum\left(\mathrm{E}_{o}^{G H E} \cdot e_{\tau}^{o}\right)
\end{aligned}
$$




\begin{tabular}{|c|c|c|c|c|c|c|c|}
\hline \multirow{2}{*}{ 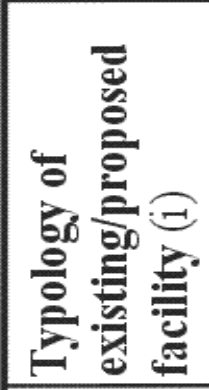 } & \multirow{2}{*}{ 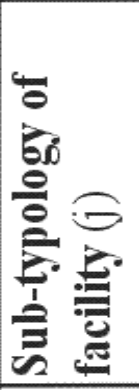 } & \multirow{2}{*}{ 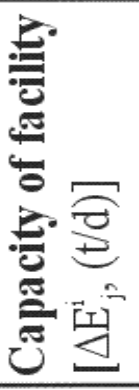 } & \multirow{2}{*}{ 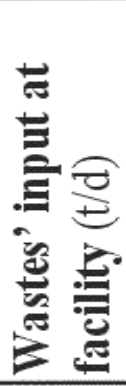 } & \multirow{2}{*}{ 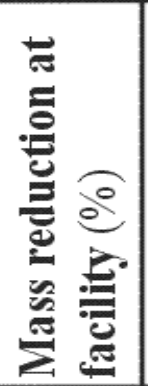 } & \multirow{2}{*}{ 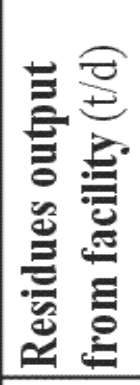 } & \multirow{2}{*}{ 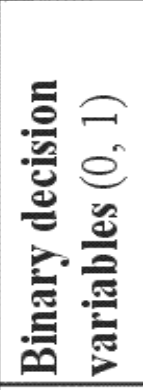 } & \multirow[t]{2}{*}{$\begin{array}{l}\text { Wastes' flows from } \\
\text { producers to facilities } \\
\text { and was tes'/residues' } \\
\text { flows from facilities to } \\
\text { other facilities/landfills }\end{array}$} \\
\hline & & & & & & & \\
\hline $\begin{array}{l}\text { Transfer } \\
\text { station }\end{array}$ & $\mu$ & $\mathrm{k}$ & b & & $\mathbf{t}$ & $\varphi_{\pi}^{\mu}$ & \\
\hline $\begin{array}{l}\text { Material } \\
\text { recovery }\end{array}$ & $v$ & $\mathrm{~g}$ & c & $\mathrm{f}_{\mathrm{MRF}}$ & $\mathrm{S}$ & $\chi_{p}^{v}$ & \\
\hline $\begin{array}{l}\text { Energy } \\
\text { recovery }\end{array}$ & $\xi$ & h & d & $\mathbf{f}_{\mathrm{WTE}}$ & q & $\psi_{\sigma}^{\xi}$ & \\
\hline Landfill & O & $\mathbf{u}$ & e & & & $\omega_{\tau}^{\circ}$ & \\
\hline
\end{tabular}

Figure 1. Four primary levels of a hierarchical facility allocation system

(Criterion-2) Final disposal, i.e. the amount of solid wastes from waste producers and transfer stations, as well as the residues from material recovery facilities and wasteto-energy facilities that are finally disposed at sanitary landfills (kt/year to be minimized - Equation 2, cf. Figure $1)$.

$$
\begin{aligned}
& \min F I D I=\sum_{o} \sum_{i} \sum_{\tau} \eta_{i \tau}^{o} \cdot \omega_{\tau}^{o} \\
& +\sum_{\mu} \sum_{o} \sum_{\pi} \sum_{\tau} \imath_{\pi \tau}^{\mu o} \cdot \omega_{\tau}^{o} \\
& +\sum_{\xi} \sum_{o} \sum_{\sigma} \sum_{\tau} \delta_{\sigma \tau}^{\xi o} \cdot \omega_{\tau}^{o}
\end{aligned}
$$

(Criterion-3) Energy recovery i.e., the recovered energy amount from waste-to-energy facilities and sanitary landfills $(\mathrm{MWh} /$ year, to be maximized - equation 3, cf. Figure 1, Table 2).

$$
\begin{aligned}
\max E R_{j} & =\sum_{v} \sum_{\rho}\left(\mathrm{A}_{j}^{E} \cdot c_{\rho}^{v}\right) \\
& +\sum_{\xi} \sum_{\sigma}\left(\Gamma_{j}^{E} \cdot d_{\sigma}^{\xi}\right) \\
& +\sum_{o} \sum_{\tau}\left(\mathrm{E}_{j}^{E} \cdot e_{\tau}^{o}\right)
\end{aligned}
$$

(Criterion-4) Material recovery i.e., the amount of recovered materials from material recovery facilities (kt/year to be maximized - Equation 4, cf. Figure 1, Table 3)

$$
\begin{aligned}
& \max M R_{j}=\sum_{v} \sum_{\rho}\left(\mathrm{A}_{j}^{M} \cdot c_{\rho}^{v}\right) \\
& +\sum_{\xi} \sum_{\sigma}\left(\Gamma_{j}^{M} \cdot d_{\sigma}^{\xi}\right)
\end{aligned}
$$

Criterion-5) total specific financial cost, i.e. facility investment-/operating cost, as well as transportation cost $(€ / t$, to be minimized - Equation 5, Figure 2, Table 4).

Table 1. Emission coefficients for greenhouse effect (equivalent $\mathrm{ktco}_{2}$ /year - Kolar, 1990; Baldasano and Cremades 1995; IPTS, 1999).

$$
\begin{gathered}
\text { Emission } \\
\text { coefficient }
\end{gathered} \quad \tilde{\mathrm{A}}_{i}^{\mathrm{GHE}} \quad \AA_{i}^{\mathrm{GHE}}
$$

Facility

$\begin{array}{ll}\text { Rotary kiln } & 53,89 \\ \text { RDF } & 53,83\end{array}$

Landfill

Table 2: Energy recovery coefficients (MWh • day/twaste $\cdot$ year) concerning corresponding waste management facilities (Karagiannidis, 1996).

\begin{tabular}{cccc}
\hline $\begin{array}{c}\text { Facility (j) } \\
\text { Coefficient }\end{array}$ & RDF & $\begin{array}{c}\text { Rotary } \\
\text { kiln }\end{array}$ & Landfill \\
\hline$\tilde{\AA}^{\mathrm{E}}{ }_{\mathrm{j}}$ & 96,7 & 93,6 & \\
\hline$\AA_{\mathrm{j}}^{\mathrm{A}}$ & & & 42,7 \\
\hline
\end{tabular}

Table 3: Coefficients for calculating the material recovery from waste management facilities (Karagiannidis, 1996)

\begin{tabular}{lcc}
\hline Facility (j) $\quad$ Coefficient & $\mathbf{A}^{\mathbf{M}}{ }_{\mathbf{i}}$ & $\tilde{\mathbf{A}}^{\mathbf{M}}{ }_{\mathbf{i}}$ \\
\hline Material recovery facility & 120,0 & \\
RDF & & 75,0 \\
\hline
\end{tabular}




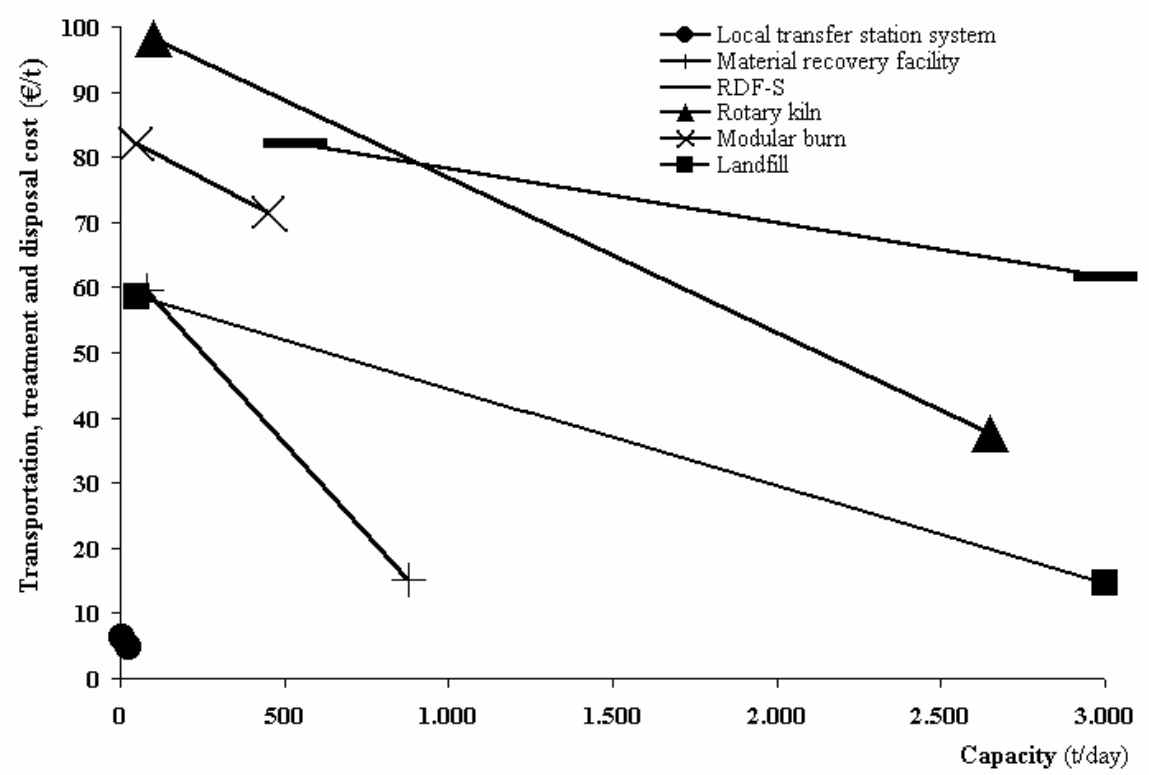

Figure 2. Total cost for the transportation, treatment and final disposal of solid wastes in accordance with facility capacity, (Kamgiannidis, 1996, Perkovlidis, 2001)

$$
\begin{aligned}
\max F T & =\sum_{\mu} \sum_{\pi}\left[C F F_{\varphi}^{\mu} \cdot \varphi_{\pi}^{\mu}+C F V_{\varphi}^{\mu} \cdot b_{\pi}^{\mu}\right] \\
& +\sum_{v} \sum_{\rho}\left[C F F_{\chi}^{v} \cdot \chi_{\rho}^{v}+C F V_{\chi}^{v} \cdot c_{\rho}^{v}\right] \\
& +\sum_{\xi} \sum_{\sigma}\left[C F F_{\psi}^{\xi} \cdot \psi_{\sigma}^{\xi}+C F V_{\sigma}^{\xi} \cdot d_{\sigma}^{\xi}\right] \\
& +\sum_{o} \sum_{\tau}\left[C F F_{\omega}^{o} \cdot \omega_{\tau}^{o}+C F V_{\omega}^{o} \cdot e_{\tau}^{o}\right]
\end{aligned}
$$

where $\tau_{0} \mathrm{CFF}_{\mathrm{i}}^{\mathrm{j}}$ represents the fixed cost per each one solid waste management facilities $(€ / \mathrm{t})$ and $\mathrm{CFV}_{\mathrm{i}} \mathrm{j}^{\mathrm{j}}$ represents the variable cost for transport, treatment and final disposal of the wastes ( $€ /$ day).

Each solution resulting from the 5 aforementioned linear models are hence called 'scenario'. The constraints of each derived model refer to:

(a) Service demand, i.e. the produced amount of wastes is equal to the sum of capacities from the facilities of the system (Equation 6, cf. Figure 1).

$$
\begin{aligned}
& a_{i}=\sum_{\mu} \sum_{\pi} \alpha_{i \pi}^{\mu}+\sum_{\nu} \sum_{\rho} \varepsilon_{i \rho}^{v} \\
& +\sum_{\xi} \sum_{\sigma} \zeta_{i \sigma}^{\xi}+\sum_{o} \sum_{\omega} \eta_{i \omega}^{o}
\end{aligned}
$$

(b) Facility capacity. This constraint concerns the relationship between the planning capacity of the facility (upper capacity limit in Table 4) and the arriving flows (wastes or residues): b1) $b^{\mu}<<\kappa^{\mu} \cdot \varphi^{\mu}{ }_{\pi}$ (local transfer stations), b2) $c_{\rho}^{v}<g^{v}{ }_{\rho} . \chi_{\rho}^{v}$ (material recovery facilities), b3) $d_{\alpha}^{\xi_{\alpha}}<h_{\alpha}^{\xi_{\alpha}} \cdot \psi^{\xi_{\alpha}}$ (energy recovery facilities) and $\mathrm{b} 4) e_{\tau}^{0}<u_{\tau}^{0} \cdot \omega_{\tau}^{\mathrm{o}}$ (landfills).

(c) Mass input-output relation at facilities. In case this constraint refers to local transfer stations, then the equation $b_{\pi}^{\mu}=t_{\pi}^{\mu}$ (mass conservation) is in effect. In case of a treatment facility, then the equations $f^{v} . c^{\nu} \rho$ $=s^{\nu} \rho$ and $f^{\xi} \cdot d^{\xi} \sigma=q \xi$ are in effect for material recovery facilities and WTE facilities, respectively. The $f^{v}$ and $f \xi$ coefficients are chosen from databases, which resulted from bibliographic data elaboration of material recovery facilities and incinerators (Michos and Pazvanti, 1999; Kampataidis, 1998; and Katsameni and Korakis, 1996).

(d) Compactor- and truck-capacity, maximum allowed gross truck weight and speed limits. Solid wastes were allowed to either leave transfer stations uncompressed (in the case that they are sent to material recovery facilities, by mostly open- containers), or compressed (in the cases they are sent to waste-to energy facilities or landfills).

The location of waste management facilities becomes more complicated due to the resulting necessity for multicriteria evaluation and classification of alternative solutions. In this work, a knowledge base, Figure 3, in combination with a database of solid waste management facilities in Greece (Moussiopoulos et al., 2000) and a relative model generator (Karagiannidis and Moussiopoulos, 1998), was used for the formulation of the location system and the multicriterial analysis of waste flow allocation. 


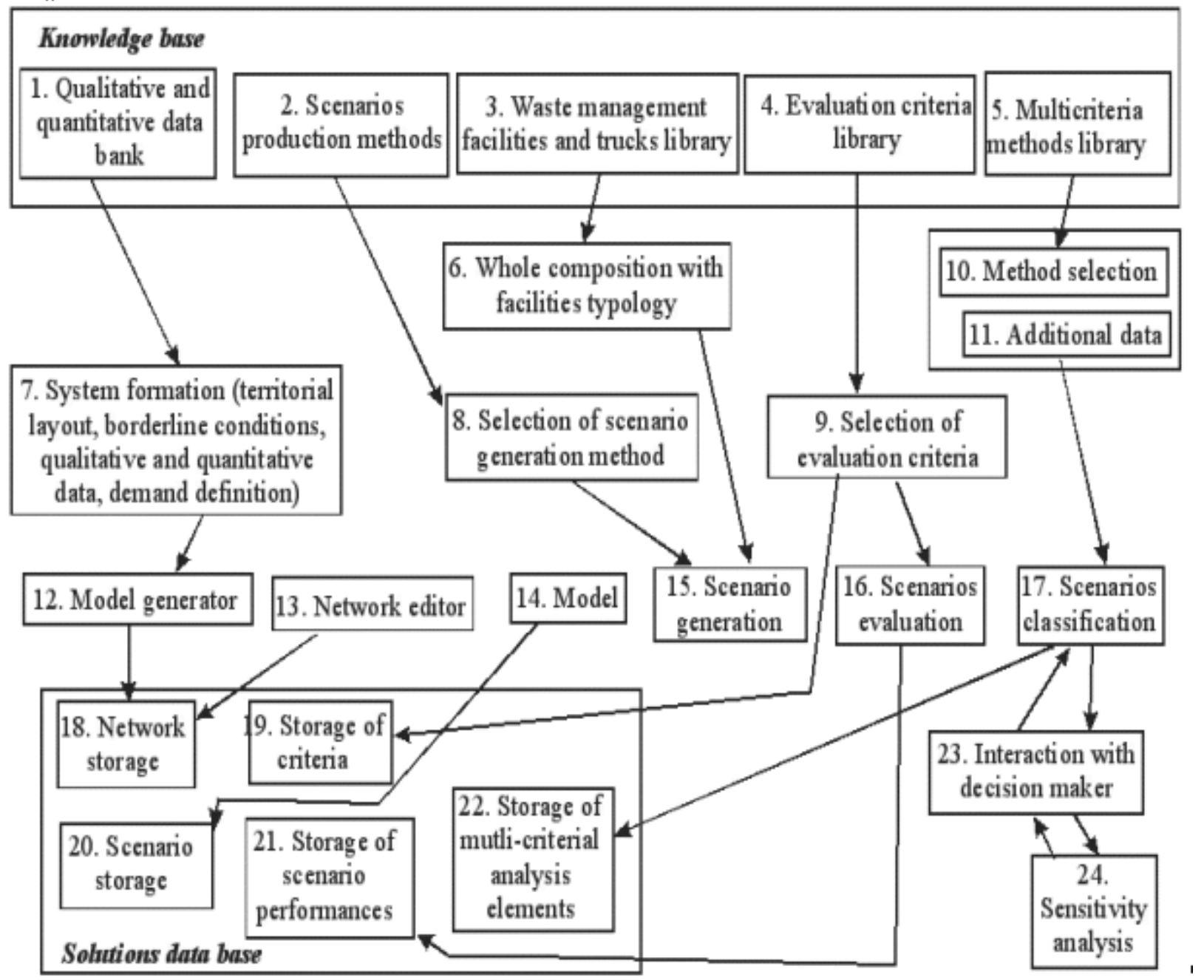

Figure 3. Proposed generic structure of the model-generating framework for integrated waste management models (Karagiannidis, 1996)

\section{The Case Study Area}

The Region of Peloponnese has a population of $1,171, .000$ and lies on the southern edge of mainland Greece, Figure 4. From an administrative point of view, the Region is composed of 7 prefectures: Ilia, Korinthia,
Argolis, Achaia, Laconia, Arkadhia and Messinia. The Region is mostly highland, while there are some fertile plains, which mainly stretch along coastal zones. There are intense inter-district inequalities at the Region, due to its separation to industrial and highland zones. Three main road networks lead to places with abundant physical beau-

Table 4. $\mathrm{CFF}_{\mathrm{i}} \mathrm{j}_{\text {and }} \mathrm{CFV}_{\mathrm{i}} \mathrm{j}_{\mathrm{j}}$ coefficients for calculating the total cost for the transportation, treatment and final disposal of solid wastes (Karagiannidis, 1996, Karagiannidis at al., 1996, Perkovlidis, 2001)

\begin{tabular}{lcccccc}
\hline \multicolumn{1}{c}{ Facility } & $\begin{array}{c}\text { Capacity Range } \\
(\boldsymbol{t} / \boldsymbol{d})\end{array}$ & $\begin{array}{c}\text { Investment } \\
\text { Cost Range } \\
(\boldsymbol{\epsilon} / \boldsymbol{t})\end{array}$ & $\begin{array}{c}\text { Operational } \\
\text { Cost Range } \\
(\boldsymbol{\epsilon} / \boldsymbol{t})\end{array}$ & $\begin{array}{c}\text { Total Cost Range } \\
(\boldsymbol{\epsilon} / \boldsymbol{t})\end{array}$ & $\mathbf{C F V}_{\mathbf{i}}^{\mathbf{j}}$ & $\mathbf{C F F}_{\mathbf{i}}{ }^{\mathbf{i}}$ \\
\hline $\begin{array}{l}\text { Landfill } \\
\text { Local transfer }\end{array}$ & $50-3,000$ & - & - & $57.00-18.00$ & -0.01 & 57.66 \\
$\begin{array}{l}\text { station } \\
\text { Material recovery }\end{array}$ & $5-25$ & $2.31-0.71$ & 4.11 (const) & $6.42-4.82$ & -0.08 & 6.82 \\
facility & $80-880$ & $11.42-7.78$ & $48.06-7.33$ & $59.48-15.11$ & -0.06 & 63.92 \\
RDF-S & $530-3,000$ & $21.08($ const) & $61.10-41.26$ & $82.18-62.34$ & -0.01 & 86.44 \\
Rotary kiln & $100-2,650$ & 26.66 (const) & $71.52-10.99$ & $98.18-37.65$ & -0.02 & 100.55 \\
\hline
\end{tabular}




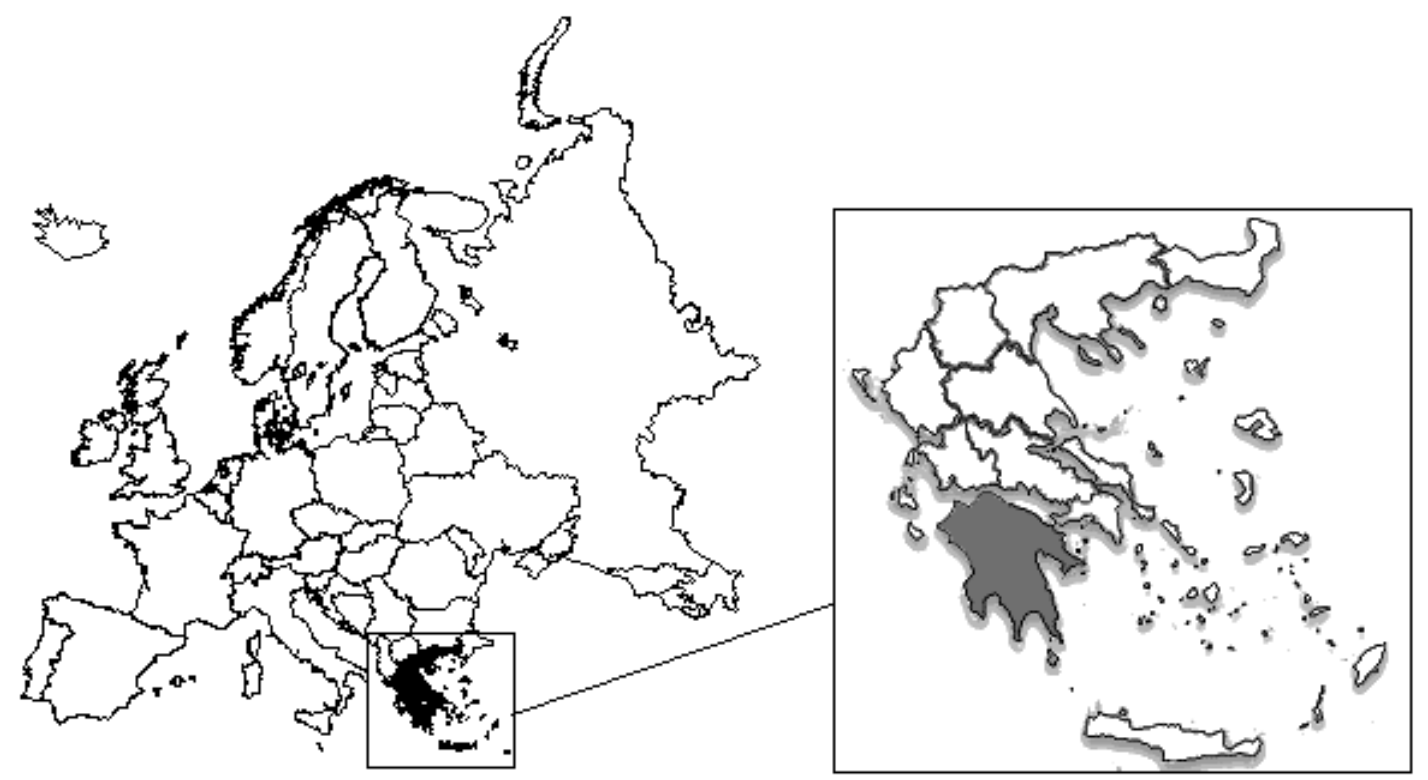

Figure 4. Case-study area (stippled)

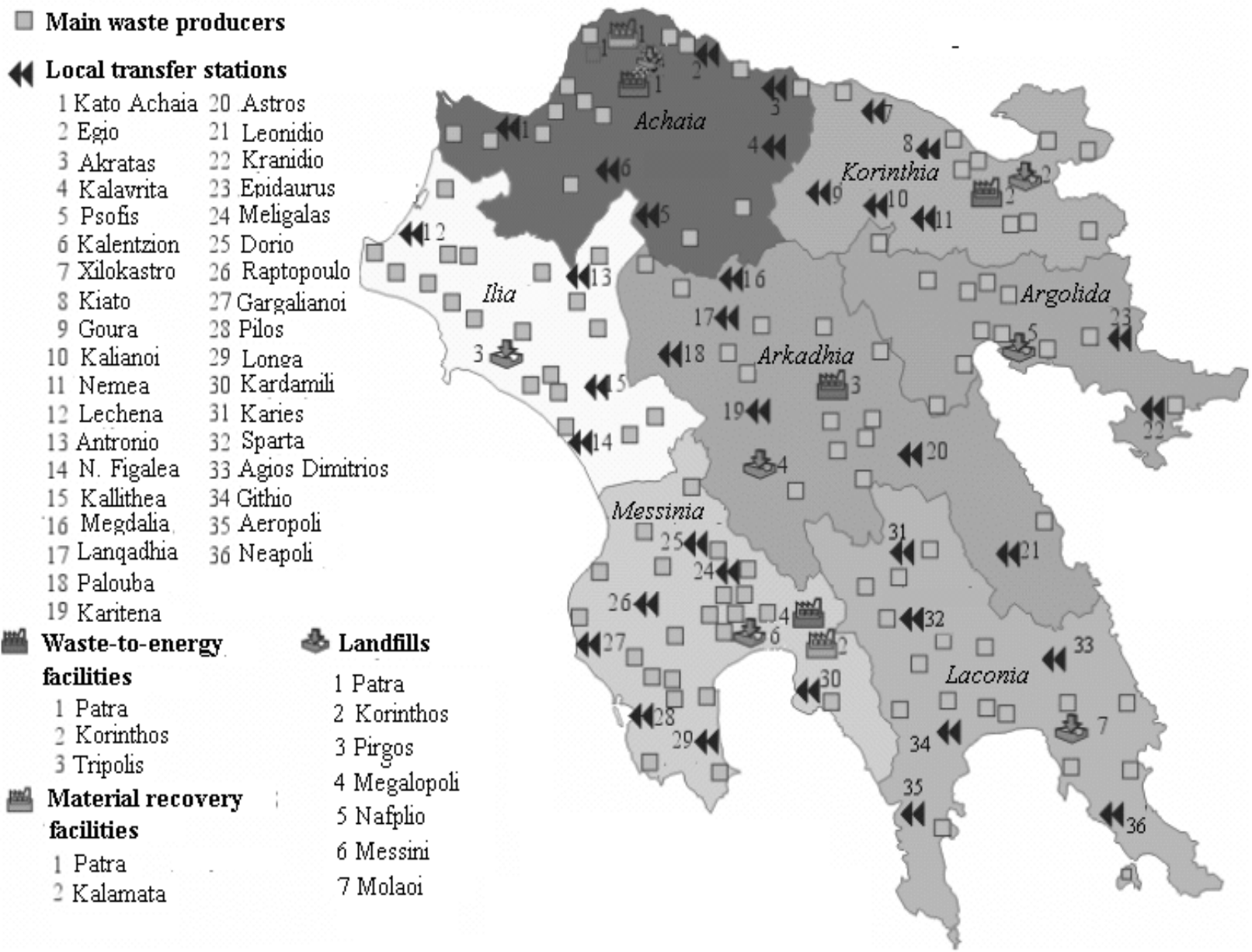

Figure 5. Existing and candidate facilities in case study area 
ty and important archaeological sites.

The solid waste collection system in the Region of Peloponnese covers $90 \%$ of its population. Here, it should be mentioned that the number of existing uncontrolled landfills is estimated at about 1,000 at the time of the study. The produced amount of wastes is 400,000 t/year. Concerning solid waste management facilities, the Municipality of Patra has proposed the creation of a multicollecting recycling program, where the construction of one material recovery facility is included. There is also already one sanitary landfill in operation in Patra. Its new cell, with a budget of 2,932,600€, operates since 1995 and it is estimated that it will cover the needs of Municipality for 15 years. Furthermore, there is one material recovery facility in Kalamata with a total capacity of $400 \mathrm{t} / \mathrm{week}$, which serves the homonymous municipality since 1997. Finally, reported plans concerning the construction of one sanitary landfill in Korinthos, were also taken into consideration, Figure 5.

In this work, the 37 municipalities of the Region of Peloponesse were considered as main waste producers. Related quantitative data is given at Table 5. Due to the dispersion of producers, the transport of produced wastes to distant facilities was proposed to take place by local transfer systems. Finally, it was assumed that energy recovery is performed at all proposed landfills through collection and treatment of the produced biogas, thus also reducing the emitted methane, which contributes significantly to the greenhouse effect (Energy Information Administration, 1999).

The Region of Peloponesse is scheduled to be connected in the near future to the natural gas national network, but at the time the study was conducted it depended solely on the use of lignite for its energy demands. For this reason, the creation of WTE facilities in industrial areas with increased energy demand was proposed (cf. Figure 5). From the application of the model, five decentralized scenarios resulted as alternative solutions concerning the management of solid wastes for each of the five evaluation criteria: 1) minimal impact to the greenhouse effect (scenario 1), 2) minimal amount of landfilled wastes and residues (from the treatment of wastes) to landfills (scenario 2), 3) maximal energy recovery (scenario 3), 4) maximal material recovery (scenario 4) and 5) minimal total cost for the management of produced wastes (scenario 5). Here it should be mentioned that due to the increased dispersion of solid waste management facilities and also due to the emphasis on local management at the period of the study, all five scenarios have a strongly local character (i.e. one landfill per prefecture - Figure 6). The capacities of existing facilities (landfill in Patra and material recovery facility in Kalamata) were set as constant. The results are presented at Table 6.

\section{Multicriterial Evaluation of Results}

In the following multicriterial approach, all five aforementioned criteria were used. The performances of the five scenarios in all criteria were calculated by means of a pre-compiled knowledge base (Karagiannidis et al., 1996). It must be emphasized that these were quite close to each other in all scenarios (cf. Table 6) due to their decentralized character and the assumption that a great number of facilities existed variable capacity, which was in accordance with the expressed preferences of local decision makers (Drossos and Terzopoulos, 1999). Therefore, apart from the already existing facilities, local authorities of the Region have already expressed their interest for specific candidate facilities (cf. Figure 5).

For global evaluation and ranking purposes, the multi-

Table 5. Produced wastes in the region of Peloponnese

$\begin{array}{lcclcc}\text { Prefecture } & \begin{array}{c}\text { Number of } \\ \text { municipalities }\end{array} & \begin{array}{c}\text { Produced } \\ \text { wastes (t/day) }\end{array} & \text { Prefecture } & \begin{array}{c}\text { Number of } \\ \text { municipalities }\end{array} & \begin{array}{c}\text { Produced wastes } \\ (\mathrm{t} / \text { day) }\end{array} \\ \text { Ilia } & 22 & 210 & \text { Laconia } & 22 & 108 \\ \text { Korinthia } & 15 & 166 & \text { Arkadhia } & 23 & 122 \\ \text { Argolis } & 16 & 111 & \text { Messinia } & 31 & 196 \\ \text { Achaia } & 23 & 436 & \text { Total } & \mathbf{1 5 2} & \mathbf{1 . 3 4 9}\end{array}$

Table 6. Performance of the five scenarios

$\begin{array}{cccccc}\begin{array}{c}\text { Greenhouse effect } \\ \text { (equivalent } \\ \text { ktco } 2 \text { (year) }\end{array} & \begin{array}{c}\text { Final disposal in } \\ \text { landfill (kt/year) }\end{array} & \begin{array}{c}\text { Energy recovery } \\ (\text { GWh/year) }\end{array} & \begin{array}{c}\text { Material recovery } \\ (\boldsymbol{k t} \text { /year) }\end{array} & \begin{array}{c}\text { Total financial } \\ \text { cost }(\boldsymbol{E} / \boldsymbol{t})\end{array} \\ 1 & 311 & 388 & 69 & 17 & 87 \\ 2 & 376 & 356 & 63 & 17 & 86 \\ 3 & 339 & 389 & 67 & 17 & 87 \\ 4 & 316 & 387 & 67 & 18 & 87 \\ 5 & 376 & 358 & 63 & 17 & 86\end{array}$




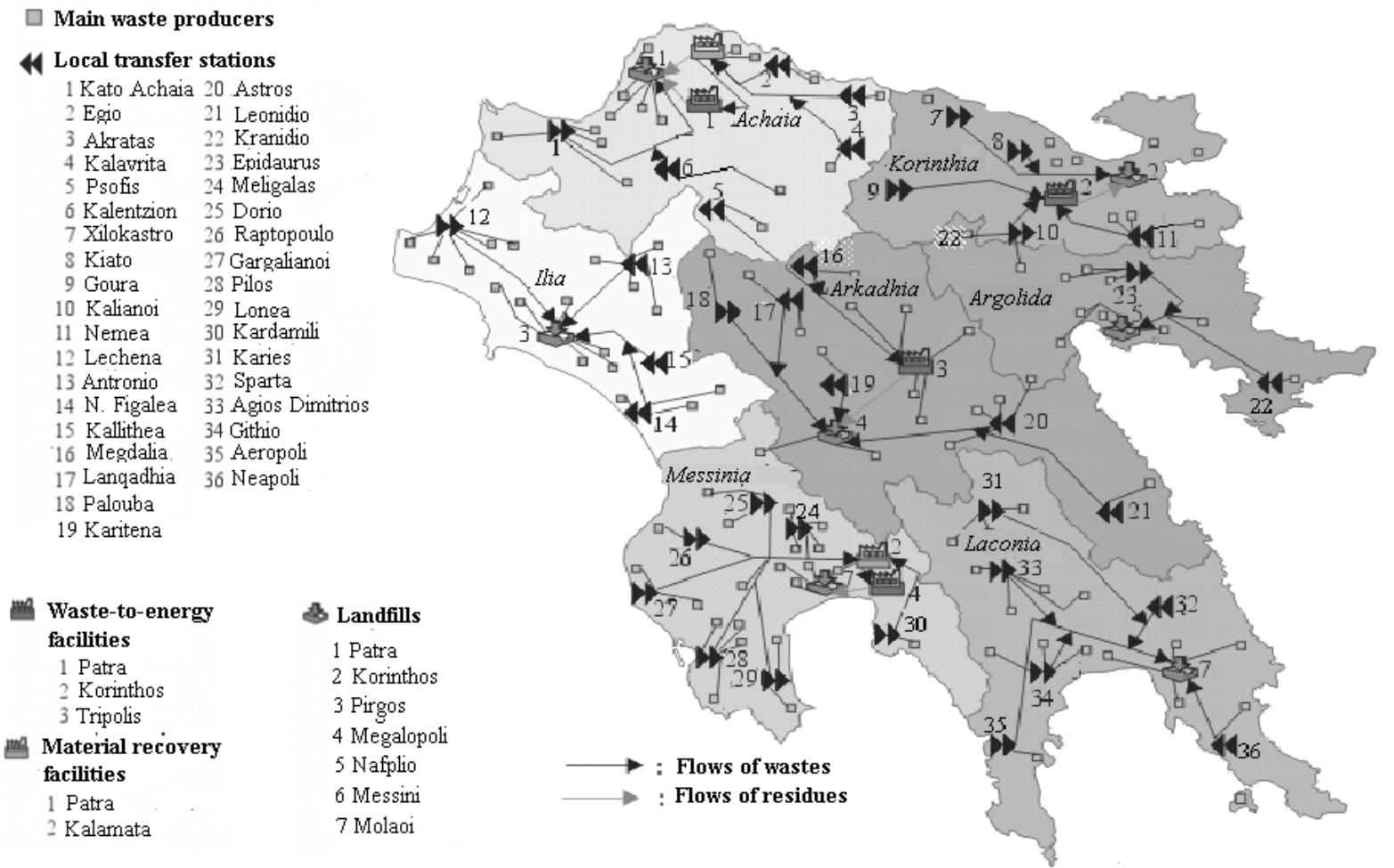

Figure 6. Best alternative solution for location of facilities and allocation of wastes flows

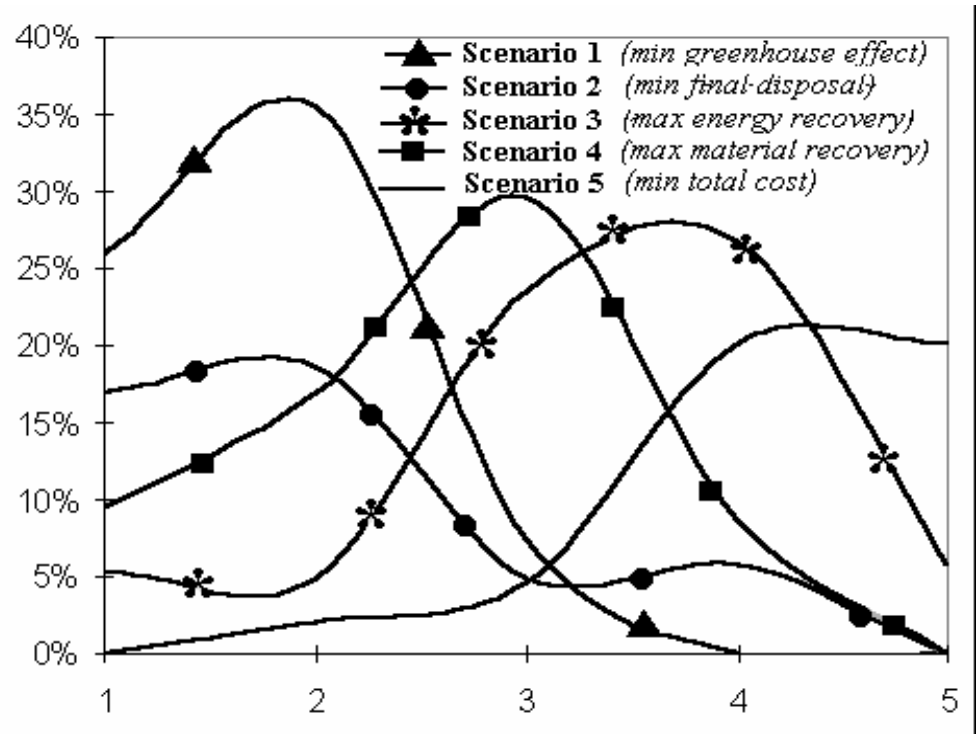

Figure 7. Frequency distribution of each scenario's ranking (position 1: best; position 5: worst) for the 243 considered weight combinations used in sensitivity analysis

criterial approach was chosen. Multi-attribute utility theory, compromising programming, goal programming and discrete methods have been developed as specific multicriterial techniques. In this context, the well-established ELECTRE III multicriterial method (Rogers and Bruen, 1998a-b; Roy, 1986; 1990) was applied in the present study. A total of 243 independent weight combinations were derived from the sensitivity analysis, which resulted from $50 \%$-step on the 5 criterion-weights (i.e. $0 \%, 50 \%$ and $100 \%$ ). The frequency distribution of the five positions of each scenario is given in Figure 7.

\section{Conclusions and Discussion}

Scenario 1 (min of greenhouse effect) was ranked best at $26 \%$ (63 cases) in the sensitivity analysis. It was followed by scenario 2 (min final disposal), which appeared at the top $17 \%$ of all rankings (cf. Figure 7). Scenario 1 combines recycling and thermal treatment of wastes. Here, it should be mentioned that the same candidate facilities were proposed as existing in all scenarios. Thus, the best alternative scenario also gives the optimal facility capacities (cf. Figure 6). Furthermore, scenario 1 is second-best 
in terms of cost, following scenarios 2 and 5 (table 6). As far as the second-best position is concerned, scenario 1 (min greenhouse effect) is placed there more frequently than all the others (i.e. $35 \%$ of all cases).

The proposed construction of a material recovery facility near the landfill of Patra is in agreement with recent European legislation concerning the diversion of biodegradable wastes from landfills. Furthermore, its existence will facilitate the continuous and steady flow of residue-derived-fuel to the waste-to-energy facility that is proposed to be located close to the city of Patra, an area with high energy demand. Three waste-to-energy facilities are proposed to be located in industrial areas with high energy demand. Finally, seven landfills are proposed in the entire Region, one for each prefecture.

The proposed thirty-six local transfer stations can also be used as drop-off centers for recycling and sending compressed and/or uncompressed wastes to facilities at relatively large distances. They can also contribute to the decommissioning of 'wild' landfills (uncontrolled tipping sites), where the open incineration of wastes causes various forms of pollution. Obviously, their existence reduces the total cost of solid waste management. Furthermore, it should be mentioned that the best alternative solution concerning the proposed construction of a waste-to-energy facility and a material recovery facility in Patra will combine incineration and recycling programs and therefore greatly reduce the volume of landfilled material. By operating effective recycling and collection programs, the prime concerns associated with MSW incineration, i.e. the emissions of heavy metals, acid gases and toxic substances will be minimized (Morrison et al., 1997).

In conclusion, an optimal alternative solid waste management scenario was presented in this paper for a Region in Southern Greece in accordance with current legislation (both Hellenic and European) concerning waste management (Common Ministerial Decision 114218, 1997; Common Ministerial Decision 69728/824, 1996; Common Ministerial Decision 113944, 1997; Directive 369, 1989; Directive 105, 1997). The final placement of facilities and the allocation of wastes and/or residues to them were influenced by: a) the morphological characteristics of the Region, b) the existing road network, c) the physiognomy of grounds (i.e. industrial, agricultural, urban areas) and d) the preferences of local authorities involved in the waste management activities.

Finally, future research should consider a more centralized location of facilities (i.e. one landfill or treatment facility that will be used by at least two prefectures). Thus, inter-prefectural collaborations could also be enhanced in the frame of regional integration of Solid Waste Management.

\section{References}

Anatoliki, S. A., 1999, "Study of Thessaloniki's Prefectural Framework for Integrated Solid Waste Management," Anatoliki S.A. Development Agency of Eastern Thessaloniki, Funded by the Prefecture of
Thessaloniki, according to the new European legislation 91/156, 94/62 (in Greek).

Anderson, L.E., 1968, "A mathematical model for the optimization of a waste management system," University of California at Berkeley, Sanitary Engineering Research Laboratory, SERL Report, USA, No. 68-1.

Anderson, L.E., and Nigam, A.K. 1967, "A mathematical model for the optimization of a waste management system," ORC 67-25, Operations Research Centre, University of California, Berkeley.

Association of Thessaloniki Municipalities., 1999, "Planning of solid waste management in the Prefecture of Thessaloniki," (in Greek).

Baldasano, J., and Cremades, L., 1995, "Atmospheric impact of a municipal wastes incinerator," International Journal of Environment and Pollution, Vol. 5, No. 4-6, pp. 538-547.

Bontoux, Laurent (1999), "The incineration of waste in Europe: Isasues and Perspectives," A Report for the Committee for Environment, Public Health and Consumer Protection of the European Parliament, european Commission Joint Research Centre, EUR 18717 EN, IPTS, March.

Caruso, C., Colorni, A., and Paruccini, M., 1993, "The regional urban solid waste management system, a modelling approach," European Journal of Operational Research, Vol. 12, pp. 19-28.

Common Ministerial Decision 69728/824, 1996, “ Measurements and terms for solid waste management," (in Greek), Government Paper 358.

Common Ministerial Decision 113944, 1997, "National planning for solid waste management," (in Greek), Government Paper 1016.

Common Ministerial Decision 114218, 1997, "Formation of norm standards and general programs for solid waste management, National planning for solid waste management, General Directions of Solid Waste Management," (in Greek), Government Paper 1016.

Common Ministerial Decision 14312/1302, 2000, "Completion and specialization of Common Ministerial Decision 113944/1944/1997 on National planning for solid waste management (General Directions of Solid Waste Management)," Government Paper 723, 1016/1997 (in Greek).

Council Directive 91/156/EEC, 1991, Amending Directive 75/442/EEC on waste, 18 March. Directive 369 (1989), On the prevention of air pollution from new municipal waste incineration plants.

Directive 105, 1997, "Proposal direction of the Council concerning the leadfilling of wastes".

Drossos, E., and Terzopoulos, P., 1999, "Multicriterial evaluation of best alternative solid waste management activities: Implementation of ELECTRE III at the Region of Peloponnese," Diploma Thesis, Laboratory of Heat Transfer and Environmental Engineering, Department of Mechanical Engineering, Aristotle University of Thessaloniki (in Greek).

Energy Information Administration, 1999, "Emissions of 
Greenhouse Gases in the United States 1998," Office of Integrated Analysis and Forecasting, DOE/EIA0573, U.S. Department of Energy, Washington, October.

Erkut, E., and Neuman S., 1992, "A multiobjective model for locating undesirable facilities," Annals of Operations Research, Vol. 40, pp. 209-227.

Esmaili H., 1972, "Facility selection and haul optimization model," Journal of Sanitary Engineering, ASCE, 98/SA6.

European Parliament and Council, 1994, Directive 62, Official Journal of the European Communities, No L 365/10, 31/12/1994.

European Parliament and Council, 1994a, Directive on Packaging and Packaging Waste (94/62/EC).

Fishbein, B., and Gelb C., 1992, "Making less garbage," a planning guide for communities, INFORM, New York.

Fuertes, L.A., Hudson, J.F., and Mark, D.H., 1974, "Solid waste management: equity trade-off models," Journal of Urban Planning Development, ASCE 100(2) (1974) 155-171.

Fulkerson, D.R., 1961, “An out-of-kilter method for minimal cost-flow problems," J. Soc. Industrial and Applied Math., Vol. 9, pp. 18-27.

Gottinger, H.W,. 1986, "A computational model for solid waste management with applications," Application of Mathematical Modeling Vol. 10, pp. 330-338.

Gottinger, H.W., 1988, "A computational model for solid waste management with application," European Journal of Operational Research, Vol. 35, pp. 350364.

Helms, B.P,. and Clark, R.M., 1971, "Locational models for solid waste management," Journal of Urban Planning and Development Division, 97/SA2.

Hokkanen, J., and Salminen, P., 1994, "The choice of a solid waste management system by using ELECTRE III MCDA method, in: Applying MCDA to Environmental Management," (M.Paruccini ed.), luwer Academic Publishers, ECSC, EEC, EAEC, Brussels and Luxembourg, pp. 111-153 (ISBN 07923-2922-8).

Hsieh, H.N., and Ho, K.H., 1993, "Optimization of solid waste disposal system by linear programming technique," Journal of Resource Management and Technology Vol. 21 (4), pp. 194 - 201.

Huang, G.H., Baetz, B.W., and Patry, G.G,. 1992, “A grey linear programming approach for municipal solid waste management planning under uncertainty," Civil Engineering Systems, Vol. 9, pp. 319-335.

Hellenic Official Gazette, Joint Ministerial Decision (JMD) 69728/824, 1996, "Measures and terms for SWM," HOG 358B/17-5-1996.

Hellenic Official Gazette, Joint Ministerial Decision (JMD) 113944/1302, 1997, "National Planning of solid WM-General Guidelines for solid WM, HOG 1016B/17-11-1997.

Hellenic Official Gazette, Joint Ministerial Decision (JMD) 114218/1302, 1997, titled "Tutoring of the specification framework and general programs for solid WM," HOG 1016B/17-11-1997.

Hellenic Official Gazette, Joint Ministerial Decision (JMD) 14312/1302,2000, titled "National planning of solid WM - General Guidelines for solid WM," HOG 723B/9-6-2000.

Kampataidis, Chr., 1998, "Evaluation of best alternative activities concerning the solid waste management activities at Central Macedonia Region, Greece," Diploma Thesis, Laboratory of Heat Transfer and Environmental Engineering, Department of Mechanical Engineering, Aristotle University of Thessaloniki (in Greek).

Karagiannidis, A., 1996, "Modelling integrated waste management," Dissertation thesis submitted to the Department of Mechanical Engineering of Aristotle University Thessaloniki (in Greek).

Karagiannidis, A., 1998, "Waste management and life cycle analysis: Two against interactive thematic unities. Life Cycle Analysis," Laboratory of Heat Transfer and Environmental Engineering, Thessaloniki, July, pp. 98-95 (in Greek).

Karagiannidis, A., P. Korakis, L., Katsameni, and Moussiopoulos, N., 1996, "A data- and criteriabase for evaluating regional management scenarios for solid waste," Proc. 5th National Congress on Renewable Energy Sources, Athens, Vol. 2, pp. 341349.

Karagiannidis, A., and Moussiopoulos, N., 1997, "Application of Electre III for the Integrated Management of Municipal Solid Wastes in the Greater Athens Area," European Journal of Operational Research, pp. 439-449.

Karagiannidis, A., and Moussiopoulos, N., 1998, "Modelling framework for solid waste regional management with explicit consideration of local features," Location Science, Vol. 6, pp. 281-305 (in Greek).

Karagiannidis, A., Perkoulidis, G., and Moussiopoulos, N., 1999a, "Applying AHP for the optimal locational-policy selection of municipal solid waste management facilities," Proc. 5th Int. Conf. "Decision Sciences Institute," (eds. D. Despotis and C. Zopounidis), Athens, Greece, 4-7 July 1999, Vol. 2, pp. 1320-1322.

Karagiannidis, A., Mousiopoulos, N., Samaras, Z., Koufodimos, G., Verganelakis K., Kouimtzis, T., Voutsa, D., and Kouras, A., 1999b, "Optimisation of Waste Management in Thessaloniki," Final Report-, Research Project Funded by: General Secretariat of Research and Technology, Thessaloniki (in Greek).

Karagiannidis, A., Moussiopoulos, N., Panagiotakopoulos, C., and Perkoulidis, G,. 2002, "Locating facilities for treatment and disposal of solid wastes: A review of current literature," Proceedings of the 1st International Conference on solid waste management, Athens, 28 February-01 March, CD (in Greek).

Katsameni, M. L., and Korakis, P., 1996," Formation of a criteria data bank for evaluating prefectural solid waste management scenarios," Diploma Thesis, 
Laboratory of Heat Transfer and Environmental Engineering, Department of Mechanical Engineering, Aristotle University of Thessaloniki (in Greek).

Kolar J., 1990, Stickstoffoxide und Luftreinhaltung, Berlin.

Kouras, A., Voutsa, D., and Kouimtzis, Th., 2001, "Characterization of bottom ash produced from combustion of fermentable matter of municipal solid wastes from Northern Greece," Fresenious Environmental Bulletin, Vol. 10 (8), pp. 669-673.

Lund, J.R., and Tchobanoglous, G., 1994, "Linear programming for analysis of material recovery facilities," Journal of Environmental Engineering, ASCE 120 (5).

Marks, D.H., and Liebman, J.C., 1970, "Mathematical analysis of solid waste management," USPHS, Bureau of Solid Waste Management.

Michos, S., and Pazvanti, E., 1999, "Multicriterial analysis of best alternative waste management scenarios. Implementation of the Analytical Hierarchy Process (AHP) at Western Macedonia Region," Greece, Diploma Thesis, Laboratory of Heat Transfer and Environmental Engineering," Department of Mechanical Engineering, Aristotle University of Thessaloniki (in Greek).

Morrison, K., Robert, H., and Cone, M., 1997, "The role of a municipal solid waste incinerator in a small community, Municipal Solid Wastes, Problems and Solutions," Ed. R. E. Landreth, P. A. Rebers, CRC Press, Inc.

Moussiopoulos, N., Karagiannidis, A., Salonikidiou, A., and Perkoulidis, G., 1998, "Waste management in Thessaloniki - Existing situation and future perspectives considering recycling, working paper in Recycling," DIAVLOS, Network of waste derived material recovery focused on Plastics and Packaging, Thessaloniki (in Greek).

Moussiopoulos, N., 2000, "Creation and development of a bank with information and data concerning waste management in Greece," Final Report, Hellenic General Secretariat of Research and Technology (1998-2000), Aristotle University Thessaloniki Department of Mechanical Engineering, National Technical University of Athens - Department of Chemical Engineering, University of Aegean Department of Environment, Thessaloniki (in Greek).

Moussiopoulos, N., 2000, "Integrated Information System for solid waste management," Funded by Hellenic General Secretariat of Research and Technology, GNOMON S.A. (1999-2000) (in Greek).

Moussiopoulos, N., Samaras, Z., Kouimtzis, Th., Karagiannidis, A., Voutsa, D., Perkoulidis, G., Koufodimos, G., and Kouras, Th., 2002, "Sampling, field work and laboratory analyses in the frame of integrated investigation of municipal solid waste management in Thessaloniki," Greece, Proceedings of the 1st Environmental Conference of Macedonia, 1 - 4 March, Thessaloniki, pp. 206-212.

Official Gazette of the Greek Government, 1999, National Planning for the solid waste management, 6/1999.

Perkoulidis, G., Karagiannidis, A. and Moussiopoulos , N., 1998, "Spreadsheet modeling of solid waste management," Proc. Int. Conf. Protection and Restoration of the Environment IV, (eds. K.L. Katsifarakis, G. P. Korfiatis, Y. A. Mylopoulos and A. C. Demetrakopoulos), Sani, July, Vol.2, pp. 628-634.

Perkoulidis, G., Karagiannidis, A., and Moussiopoulos, N., 1999, "Applying mixed-integer linear programming for the evaluation of alternative integrated municipal solid waste management schemes in the Region of Western Macedonia Greece," Studies in Regional and Urban Planning, Vol. 7, pp. 75-90.

Perkoulidis, G., 2001, "Elaboration and implementation of a multicriterial analysis and location system for investigating the perspectives of thermal treatment of solid wastes in Greece," Dissertation thesis submitted to the Department of Mechanical Engineering of Aristotle University Thessaloniki (in Greek).

Perlack, R.D., and Willis, C.E., 1985, "Multiobjective decision-making in waste disposal planning," Journal of Environmental Engineering, ASCE 111(3), pp. 373-385.

Rogers, M., and Bruen, M., 1998a, "Choosing realistic values of indifference, preference and veto thresholds for use within environmental criteria with ELECTRE," European Journal of Operational Research, Vol. 107, pp. 542-541.

Rogers, M., and Bruen, M., 1998b, “A new system for weighing environmental criteria for use within ELECTRE III," European Journal of Operational Research, Vol. 107, pp. 552-226.

Rossman, L.A., 1971, "A general model for solid waste management facility location," Department of Civil Engineering, University of Illinois, Urbana.

Roy, B., (1986), "Classement et choix en presence de criteres multiples (la methode ELECTRE)," RIRO, Vol. 8, pp. 57-75.

Roy, B., 1990, "The outranking approach and the foundations of ELECTRE methods," in C.A. Bana e Costa (ed.), Readings in Multiple Criteria Decision Aid, Springler - Verlag, pp. 155-183.

Saaty, T.L., and Alexander, J.M., 1981, "Thinking with models," Pergamon Press, Oxford.

Vuk, D., and Ko $\square$ elj, B., 1991, "Application of multicriterial analysis on the selection of the location for disposal of communal waste," European Journal of Operational Research, Vol. 55, pp.211-217.

Zhu, Z., and ReVelle, C., 1990, "A cost allocation method for facilities sitting with fixed -charge cost functions," Civil Eng. Systems Vol. 7, pp. 29-35. 